\section{Virtual reality exposure and standard exposure were both effective at 1 year for fear of flying} Rothbaum BO, Hodges L, Anderson PL, et al. Twelve-month follow-up of virtual reality and standard exposure therapies for
the fear of flying. J Consult Clin Psychol 2002 Apr;70:428-32.

\section{QUESTION: In adults with fear of flying, is short term treatment with virtual reality exposure (VRE) or standard exposure (SE) effective at 12 months?}

\section{Design}

Randomised (unclear allocation concealment*), unblinded*, controlled trial with 1 year of follow up.

\section{Setting \\ Atlanta, Georgia, USA.}

\section{Patients}

49 adults who had fear of flying and met DSM-IV criteria for specific phobia, situational type; panic disorder with agoraphobia; or agoraphobia without a history of panic disorder. Patients on the waiting list $(\mathrm{n}=19)$ received treatment after the 6 months of follow up and were not included in this analysis. $80 \%$ of participants in the treatment groups $(\mathrm{n}=30)$ completed the 12 months of follow up (mean age $39 \mathrm{y}, 71 \%$ women). All participants were included in the analysis by using last observation carried forward.

\section{Intervention}

Participants were allocated to VRE $(n=15)$ or SE $(n=15)$. 8 treatment sessions were given over 6 weeks. The first 4 sessions were identical for both groups: brief breathing retraining, cognitive restructuring, thought stopping, and hyperventilation exposure, as appropriate. Exposure was done in sessions 5-8. VRE was done in an office where participants' seats were equipped with a woofer to simulate the noise and vibration of an aircraft. Scenarios included sitting in the cabin, takeoff, landing, and flying in both calm and stormy weather. SE was done at the airport with exposure to flight related stimuli and imaginal exposure to takeoffs and landings while sitting on a commercial aircraft parked at the gate.

\section{Main outcome measures}

Fear of Flying Inventory (FFI, 33 item scale), Questionnaire on Attitudes Toward Flying (QAF), and number of patients who had flown since the 6 months of follow up.

\section{Main results}

At 12 months, both treatment groups had improved FFI scores and QAF scores. VRE and SE did not differ for scores on the FFI (mean score $90.2 v 83.1, \mathrm{p}=0.08$ ) or QAF (126.5 $v 129.6, \mathrm{p}=0.17)$. The number of adults who had flown on real flights was similar in both groups (table).

\section{Conclusion}

In adults with fear of flying, short term virtual reality exposure and standard exposure both led to reduced fear at 12 months with no difference between groups.

*See glossary. website extra

Additional information appears on the

Evidence-Based

Mental Health website

www.ebmentalhealth. com

Source of funding: National Institute of

Mental Health.

For correspondence: Dr B O Rothbaum, Department of Psychiatry and

Behavioral Sciences, Emory University

School of Medicine,

Atlanta, GA, USA.

brothba@emory.edu

Virtual reality exposure (VRE) v standard exposure (SE) for fear of flying $\dagger$

$\begin{array}{lcccc}\begin{array}{l}\text { Outcome at } \\ 12 \text { months }\end{array} & \text { VRE } & \text { SE } & \text { RBI }(95 \% \text { Cl) } & \text { NNT (Cl) } \\ \begin{array}{l}\text { Took commercial } \\ \text { flights }\end{array} & 92 \% & 91 \% & 1.5 \%(-28 \text { to } 50) & \text { Not significant }\end{array}$

\section{COMMENTARY}

It is important to show sustained effects for VRE compared with standard exposure for phobias, and the study by Rothbaum et al goes some way to achieving this goal. It is the first 12 months of follow up study of VRE and extends the follow up from the original study sample. ${ }^{1}$ Emmelkamp $e t a l^{2}$ have also recently reported a follow up of VRE versus in vivo exposure in acrophobia, with similar results to this study; however, the sample size was smaller $(\mathrm{n}=33)$, and the follow up was over 6 rather than 12 months.

Exposure in clinical practice is typically an interactive process where the therapist guides the patient and promotes exposure to the phobic stimuli rather than escape or avoidance. Because VRE offers the opportunity for the therapist to control the phobic stimuli to a greater extent than ever before, it is possible for the therapist to facilitate the exposure process. It is not clear to what extent this occurred in the present study, and, if this did happen, what effect it might have had on the outcome.

It might be assumed that the effectiveness of VRE is related to the level of replication of reality. Thus, it may be that virtual exposure where patients feel as if they are actually in the situation may be more effective than less accurate representations of reality. However, this may not be the case. For example, Gilroy et al used an approach where patients observed and controlled computer generated exposure to a phobic stimulus. ${ }^{3}$ Good outcomes were achieved even though the stimuli were very simple cartoon like figures.

Most clinicians are unlikely to possess the head mounted display apparatus. The quality of the image and the response to head movement will determine the price, which can range from several hundred to several thousand US dollars. The computer hardware required is not particularly advanced or costly, and many clinicians will have access to it.

Justin Kenardy, $\mathrm{PhD}$ The University of Queensland Brisbane, Queensland, Australia

Rothbaum BO, Hodges L, Smith S, et al. A controlled study of virtual reality exposure therapy for the fear of flying.J Consult Clin Psychol 2000;68:1020-6.

2 Emmelkamp PM, Krijn M, Hulsbosch AM, et al. Virtual reality treatment versus exposure in vivo: a comparative evaluation in acrophobia. Behav Res Ther 2002;40:509-16.

3 Gilroy L, Kirkby KC, Daniels BA, et al. Controlled comparison of computer-aided vicarious exposure versus live exposure in the treatment of spider phobia. Behavior Therapy 2000;30:733-44. 